\title{
Mutant phenotype analysis suggests potential roles for C-type natriuretic peptide receptor (NPR-B) in male mouse fertility
}

\author{
Chizuru Sogawa ${ }^{1,2^{*}}$, Yasuhiro Fujiwara ${ }^{2,3}$, Satoshi Tsukamoto ${ }^{4}$, Yuka Ishida ${ }^{4}$, Yukie Yoshii ${ }^{1}$, Takako Furukawa ${ }^{1}$, \\ Tetsuo Kunieda ${ }^{3}$ and Tsuneo Saga ${ }^{1}$
}

\begin{abstract}
Background: C-type natriuretic peptide (CNP) signaling through its receptor natriuretic peptide receptor B (NPR-B) is a key molecule for mammalian reproduction, and known to play important roles in female fertility. However, the function of these peptides in mouse male reproduction remains largely unknown. To determine the role of CNP/NPR-B signaling in male reproduction we investigated phenotype of Npr2-deficient short-limbed-dwarfism $\left(\mathrm{Npr} 2^{\mathrm{s} / \mathrm{W} / \mathrm{s} / \mathrm{W}}\right)$ mice, which have been shown to have gastrointestinal (GI) abnormalities.
\end{abstract}

Findings: In homozygous Npr2s/w/slw mice, spermatogenesis is developmentally delayed at both 2 and 4 weeks of age, with vacuolation and degenerating apoptotic germ cells being observed at 3 weeks age. However, the adult

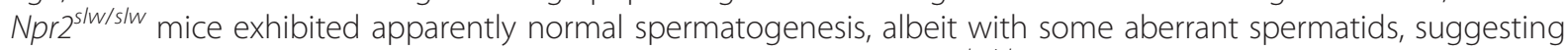
that developmental delay was overcome. In addition, the adult $N p 2^{s / w / s l w}$ mice showed abnormal penile morphology (paraphimosis).

Conclusions: The potential role of CNP signaling via the NPR-B receptor in male fertility appears to be mediated not through germ-cell development, but may be through maintenance of normal penile function.

Keywords: CNP, NPR-B, cGMP, SLW mouse, Smooth muscle, Paraphimosis, Infertility, Spermatogenesis

\section{Findings}

\section{Background}

The mouse Npr2 gene encodes natriuretic peptide receptor B, NPR-B (also known as NPR2), which is a known receptor for C-type natriuretic peptide, CNP (encoded by the $N p p c$ gene, and also known as NPPC). NPR-B synthesizes intracellular cyclic guanosine monophosphate (cGMP) [1], which acts as a secondary messenger and is degraded by cGMP-specific phosphodiesterase type 5 (PDE5) [2]. The peptide and its receptor, CNP/NPR-B are expressed in the nervous and vascular systems [3-5], including the gastrointestinal tract [6], where they are thought to act as a local paracrine or autocrine regulators [5].

A number of reports have demonstrated an important role for CNP in reproductive regulation in females [7].

\footnotetext{
*Correspondence: chizuru.f.sogawa@gmail.com

${ }^{1}$ Molecular Imaging Center, National Institute of Radiological Sciences, 4-9-1 Anagawa, Inage-ku, Chiba-shi, Chiba 263-8555, Japan

${ }^{2}$ The Jackson Laboratory, 600 Main Street, Bar Harbor, ME 04609, USA

Full list of author information is available at the end of the article
}

Although male Npr2 exhibit reduced reproductive functions, it is not known why male Npr2 mutants are infertile or sub-fertile. Most spontaneous Npr2 $2^{s l w / s l w}$ (SLW: Shortlimbed dwarfism) males fail to mate, but a limited number of these mutants generated offspring [8]. Males homozygous for another spontaneous mutation, $\mathrm{Npr} 2^{\text {pwe/pwe }}$ (peewee mouse), were sub-fertile, but exhibited normal testis histology [9]. Interestingly, the male Npr2-KO mouse was infertile but exhibited normal spermatogenesis [10]. Observations on male reproduction were mentioned only briefly in these studies and not pursued in detail.

In a previous report, it was suggested that CNP/NPR$B$ signaling could lead to relaxation of seminiferous tubules and thereby regulate sperm transportation and testicular blood supply [11]. This signaling is also believed to modulate spermatozoa motility, testicular germ cell development and testosterone synthesis in mice [12]. In addition, it was also reported that CNP regulates blood-testis barrier (BTB) dynamics in adult rats [13]. 
These reports suggested that CNP is a key factor for spermatogenesis. Therefore, it might be expected that absence of NPR-B would also impact on spermatogenesis, and indeed, reduced fertility is a phenotype in several Npr2 mutants. However, the Npr 2 mutant mice also exhibit other phenotypes that might ultimately affect fertility. For example, $\mathrm{Npr} 2^{s l w / s l w}$ mutants display gastrointestinal (GI) dysfunctions and high pre-weaning death, due to lack of CNP/NPR-B signaling $[6,14]$. In the case of the few surviving $N p r 2^{\text {slw/slw }}$ mice, the GI disorders might cause nutritional restriction, which is known to contribute to aberrant spermatogenesis and reduced number of germ cells $[15,16]$.

This study was undertaken to provide more complete and definitive observation using mice homozygous for a mutant allele of $N p r 2, N p r 2^{s l w}$, which could contribute to determination of a possible link between the $\mathrm{CNP} /$ NPR-B signaling pathway and male reproduction.

\section{Methods}

Mice

The Npr $2^{s l w}$ mutant line, herein referred to as SLW mice were maintained under standard conditions. An inbred SLW strain was created by a single backcross to the ddY mouse (Japan SLC, Inc., Shizuoka, Japan), and subsequent mating between heterozygous mice. In this study, the mice used as comparative controls were either heterozygotes or wild type for the non-mutated allele; collectively they are referred to as control. All animal experiments were carried out in accordance with institutional guidelines regarding animal care and handling, and the experimental protocol was approved by the Institutional Animal Care and Use Committee of the National Institute of Radiological Sciences.

\section{Histology and TUNEL assay}

Testes were prepared and fixed in Bouin's solution for $1 \mathrm{~h}$ (0 day postpartum (dpp)), 2 h (7 dpp), 4 h (14 dpp), overnight (21 dpp), and $24 \mathrm{~h}$ (28 dpp, $35 \mathrm{dpp}$, and adult) at room temperature (RT), and then immersed in $70 \%$ ethanol for $48 \mathrm{~h}$. The specimens were dehydrated and embedded in paraffin. Subsequently, 2 - $\mu$ m-thick sections were cut, attached to glass slides (MAS-GP Type A; Matsunami Glass Ind., Ltd., Osaka, Japan), and then deparaffinized, rehydrated, and subjected to hematoxylin and eosin staining.

The TUNEL assay was performed for detection of apoptotic cells using ApopTag ${ }^{\odot}$ Peroxidase in situ Apoptosis Detection Kit (CHEMICON ${ }^{\ominus}$ International, Inc. CA, USA) according to the manufacturer's instructions.

\section{Statistical analysis}

Data are expressed as the means \pm SD or SE. The statistical significance of differences in mean values was assessed by Student's t-test.

\section{Results}

Developmental delay of spermatogenesis in juvenile but not adult Npr2 mutant mice

As previously reported, the $N p r 2^{s l w / s l w}$ mutant mice exhibited dwarfism and GI distention with gas (Figure 1A). The testes of $N p r 2^{s l w / s l w}$ mice were smaller than control testes (Figure 1B), with the $N p r 2^{s l w / s l w}$ testis weight reduced by about $50 \%$ compared to that of control (Figure 1C). However, the testis to body weight ratio of $N p r 2^{\text {slw/slw }}$ mice was significantly larger in the $N p r 2^{s l w / s l w}$ than in control mice, reflecting the dwarfism (Figure 1D).

Histological analyses of testes of $N p r 2^{\text {slw/slw }}$ mice revealed no significant differences in overall testis appearance between the control and mutant mice at 0 and 7 dpp (Figure 2A, B, C, D). At $14 \mathrm{dpp}$, there was evidence of delay in onset and progress of spermatogenesis in

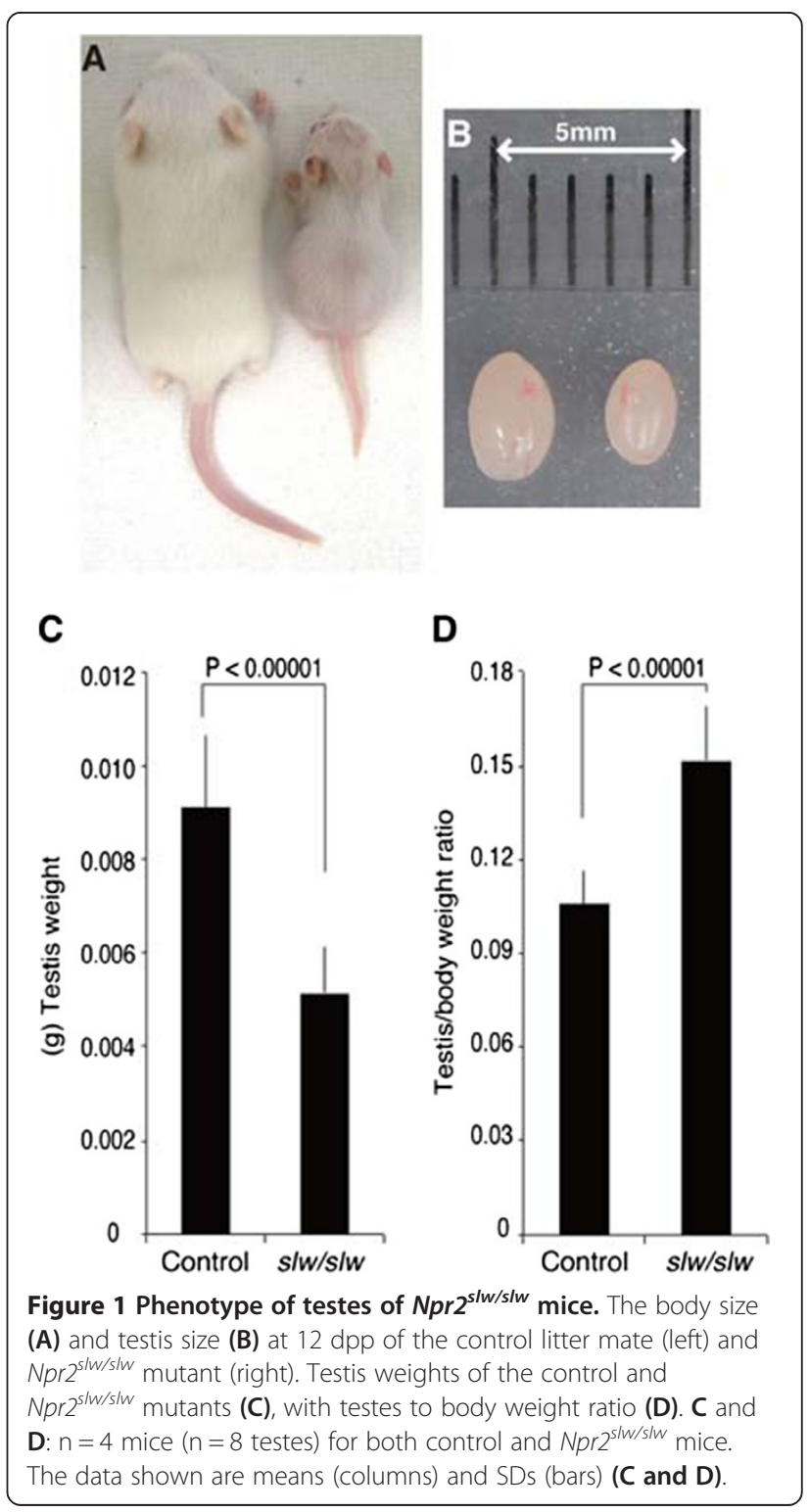




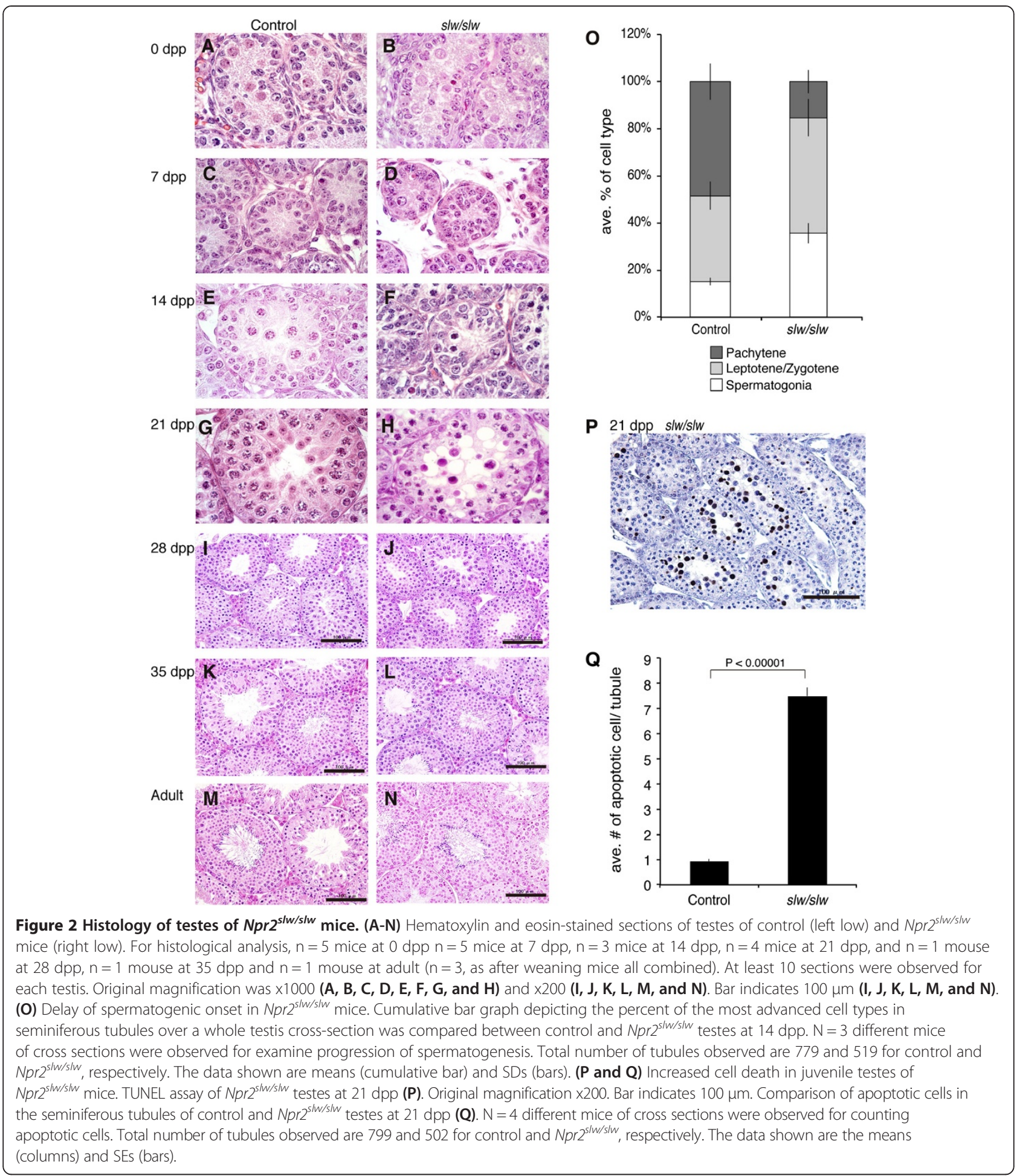

$N p r 2^{s l w / s l w}$ compared to control mice (Figure 2E, F, and $\mathrm{O})$; additionally vacuolization and presence of eosinophilic cells in the seminiferous epithelium was observed in the $N p r 2^{s l w / s l w}$ testes, but not in control testes, at 21 dpp (Figure 2G, H). At $28 \mathrm{dpp}, N p r 2^{\text {slw/slw }}$ mouse exhibited seemingly normal spermatogenesis, however the spermatogenic cells were apparently less advanced compared to control. At this age, elongated spermatids were present in control testes, but not observed in the $N p r 2^{s l w / s l w}$ testes (Figure 2I and J), indicating delay of spermatogenic progression. However, by $35 \mathrm{dpp}$, and in adults, the $N p r 2^{s l w / s l w}$ mice exhibited normal spermatogenesis 
and germ-cell composition; spermatozoa were present in the lumens of mutant seminiferous tubules (Figure 2L and $\mathrm{N}$ ) as well as those from control mice (Figure $2 \mathrm{~K}$ and $\mathrm{M})$.

\section{Apoptosis of Npr2 mutant spermatocytes}

A TUNEL assay, performed to detect cell death, revealed that apoptotic cells were abundant in late pachytene spermatocytes in $N p r 2^{s l w / s l w}$ testes at $21 \mathrm{dpp}$ (Figure 2P). The number of apoptotic cell in $N p r 2^{s l w / s l w}$ at $21 \mathrm{dpp}$ was significantly increased compared to that of control (Figure 2Q).

\section{Paraphimosis in Npr2 mutants}

Anatomically, adult $N p r 2^{s l w / s l w}$ mice exhibited paraphimosis (erectile dysfunction (ED) accompanying a trapped foreskin), while control adult mice did not (Figure 3A and B). Although the age at which mutant males first exhibited paraphimosis varied among mutant individuals, all adult $N p r 2^{s l w / s l w}$ mice exhibited paraphimosis. Interestingly, this was a temporary condition; the paraphimosis of $N p r 2^{s l w / s l w}$ mice did not persist more than one day, although it occasionally recurred. Interestingly, males of another $N p r 2$ mutant strain, Npr2 $2^{c n-2 J / c n-2 J}$ mice, persisted (data not shown).

\section{Discussion}

This study provides the first description of the male reproductive phenotype of Npr2-deficient mice. We found that the developmental onset and acquisition of spermatogenic function is delayed in $N p r 2^{s l w / s l w}$ mutant mice, but that within 5 weeks, there is restoration of apparently normal spermatogenesis. This developmental delay of spermatogenesis suggests that $\mathrm{CNP} / \mathrm{NPR}-\mathrm{B}$ signaling may play a role in initiation of spermatogenic differentiation. However, the mutant mice did not exhibit any apparent mitotic proliferation abnormality as indicated by PCNA staining (data not shown), and as adults, the $N p r 2^{\text {slw/slw }}$ mice exhibited normal germ-cell populations. These results are consistent with the previously reported phenotypes of other Npr2 alleles, namely the Npr2-KO [10] and Npr $2^{\text {pwe }}$ mouse models [9]. Thus we conclude that although CNP/ NPR-B signaling is essential for oocyte meiotic arrest in the female mouse $[7,17]$, CNP/NPR-B signaling has different roles in males because spermatogenesis did not suffer meiotic arrest, and thus CNP/NPR-B signaling is not essential for mouse spermatogenesis.

What then might cause the infertility of males bearing homozygous Npr 2 mutations? Possibly malnutrition could play a role. Our observations suggest that abnormalities of testis structure (e.g., vacuolization) and delays in onset of spermatogenic function are more prevalent in mice exhibiting the severe GI disorder characteristic of the $N p r 2^{s l w / s l w}$ mice. In contrast, both $N p r 2^{s l w / s l w}$ pups with a latent GI phenotype and $N p r 2^{c n-2 J / c n-2 J}$ mice, which have no apparent GI disorder, showed normal spermatogenic progression (data not shown). Indeed, $\mathrm{Npr} 2^{\text {slw/slw }}$ mice surviving to adulthood, though rare, exhibited dwarfism and appeared to be healthy, with apparently normal spermatogenesis. Thus we surmise that severe malnutrition from GI abnormalities may cause the spermatogenic delay at $14 \mathrm{dpp}$ and cell death at $21 \mathrm{dpp}$ in $N p r 2^{\text {slw/slw }}$

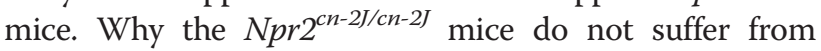
these GI problems is not clear, but may depend on the respective genetic backgrounds. These conclusions about the importance of nutrition are consistent with reports on the role of nutrition in growth and development of the reproductive system [16]; moreover, dietary restriction is known to impact negatively on testicular volume, weight and function $[18,19]$.

There may also be other explanations for the infertility of Npr2 mutant males other than physical limitations due to
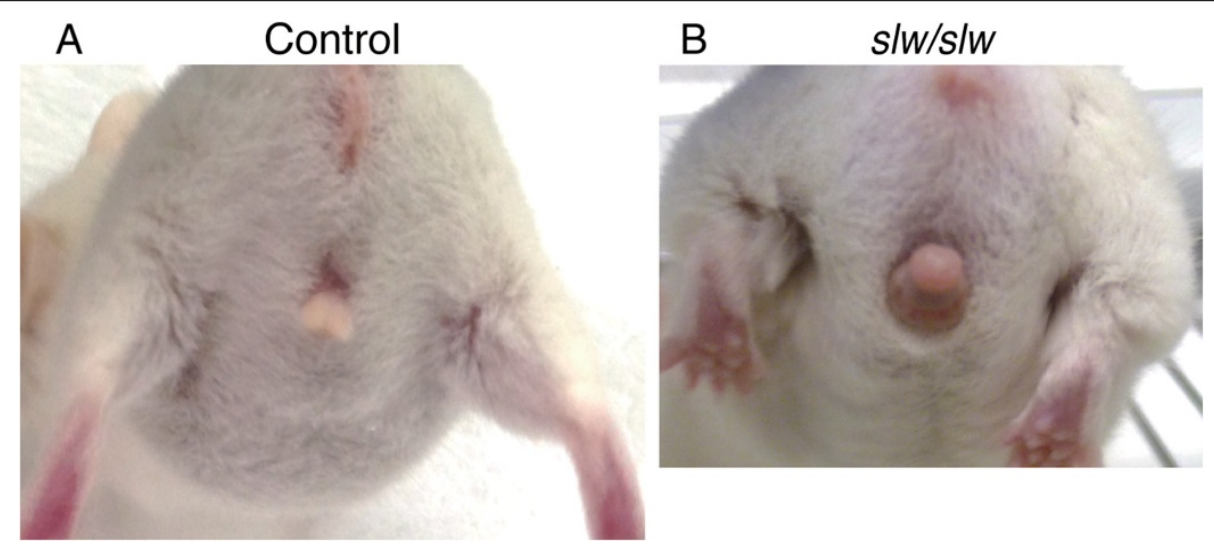

Figure 3 Paraphimosis in the adult $\mathbf{N p r} 2^{\text {slw/slw }}$. Paraphimosis in the adult $N p r 2^{s / W / s / w}$ mouse (B). $N=>10$ and a control mouse from a different litter (A). $N=>100$ 
dwarfism. The rare $N p r 2^{s l w / s l w}$ males that survive to adulthood exhibited unique and abnormal penile phenotypes, including paraphimosis and priapism [10]; this unusual phenotype was also found in adult $\mathrm{Npr} 2^{\mathrm{cn-2J} / \mathrm{Cn}-2 J}$ and $\mathrm{Npr2}$ KO mice (data not shown). Sildenafil, commonly known as Viagra $^{\circ}$ (Pfizer), a specific PDE5 inhibitor that increases concentration of cGMP by nitric oxide (NO) via soluble guanylyl cyclase (sGC) [20], has been used as a medical treatment for ED. Because CNP/NPR-B increases cGMP as well as $\mathrm{NO} / \mathrm{sGC}$ signaling, the phenotypes of Npr2-deficient mice suggest that increase and/or maintenance of cGMP is required for normal erectile function. Our previous report showed that CNP/NPR-B signaling has a critical role in smooth muscle (SM) motility in the gastrointestinal tract [6,14], and therefore prolonged erection in $N p r 2^{s l w / s l w}$ males is possibly due to abnormal function of the SM of the trabeculae corporum cavernosorum and inability to retain blood flow by contraction due to loss of cGMP production.

\section{Conclusions}

In summary, the present study suggests that NPR-Bmediated CNP signaling may play role in male reproductive function, but CNP/NPR-B signaling is not crucial for spermatogenesis. The sub-fertility in adult $N p r 2^{s l w / s l w}$ males may instead be caused by penile SM dysfunction. Future studies on CNP will provide information to understand the roles of NPR-B-mediated CNP signaling in spermatogenesis and contribute to the development of novel therapeutics for treatment of male infertility syndromes involving ED.

\section{Abbreviations}

CNP: C-type natriuretic peptide; NPR-B: Natriuretic peptide receptor B; cGMP: Cyclic guanosine monophosphate; PDE5: cGMP-specific phosphodiesterase type 5; Gl: Gastrointestinal; SLW: Short-limbed dwarfism; BTB: Blood-Testis barrier; dpp: Day postpartum; NO: Nitric oxide; sGC: Soluble guanylyl cyclase; SM: Smooth muscle; ED: Erectile dysfunction. Nomenclature for CNP and NPR-B is based on the IUPHAR pharmacology database.

\section{Competing interests}

The authors declare that they have no competing interests.

\section{Authors' contribution}

CS conceived the study, performed histological experiments, was responsible for data analysis and drafted the manuscript. YF was responsible for sampling and data analysis. ST participated in designing the study and introducing the SLW mice. YI, YY and TK participated in introducing SLW mice. TK co-supervised the study and provided SLW mice. TS supervised the study. All authors read and approved the final manuscript.

\section{Acknowledgements}

We thank Drs. John Eppig for providing Npr2 ${ }^{\text {cn-2J }}$ mice, and Mary Ann Handel for editing manuscript. This study was supported in part by a grant from the Diagnostic Imaging Program, Molecular Imaging Center, National Institute of Radiological Sciences in Japan and Japan Society for the Promotion of Science (JSPS), Strategic Young Researcher Oversea Visits Program for Acceleration Brain Circulation.

\section{Author details}

'Molecular Imaging Center, National Institute of Radiological Sciences, 4-9-1 Anagawa, Inage-ku, Chiba-shi, Chiba 263-8555, Japan. ${ }^{2}$ The Jackson Laboratory, 600 Main Street, Bar Harbor, ME 04609, USA. ${ }^{3}$ Graduate School of Environmental and Life Science, Okayama University, 1-1-1 Tsushima-naka, Kita-ku, Okayama-shi, Okayama 700-8530, Japan. ${ }^{4}$ Laboratory Animal and Genome Sciences Section, National Institute of Radiological Sciences, 4-9-1 Anagawa, Inage-ku, Chiba-shi, Chiba 263-8555, Japan.

Received: 11 May 2014 Accepted: 7 July 2014

Published: 10 July 2014

\section{References}

1. Potter $L R$, Hunter $T$ : Guanylyl cyclase-linked natriuretic peptide receptors: structure and regulation. J Biol Chem 2001, 276:6057-6060

2. Pyne NJ, Arshavsky V, Lochhead A: CGMP signal termination. Biochem Soc Trans 1996, 24:1019-1022.

3. Komatsu Y, Itoh H, Suga S, Ogawa Y, Hama N, Kishimoto I, Nakagawa O, Igaki T, Doi K, Yoshimasa T, Nakao K: Regulation of endothelial production of C-type natriuretic peptide in coculture with vascular smooth muscle cells. Role of the vascular natriuretic peptide system in vascular growth inhibition. Circ Res 1996, 78:606-614.

4. Minamino N, Aburaya M, Kojima M, Miyamoto K, Kangawa K, Matsuo H: Distribution of C-type natriuretic peptide and its messenger RNA in rat central nervous system and peripheral tissue. Biochem Biophys Res Commun 1993, 197:326-335.

5. Suga S, Nakao K, Itoh H, Komatsu Y, Ogawa Y, Hama N, Imura H: Endothelial production of C-type natriuretic peptide and its marked augmentation by transforming growth factor-beta. Possible existence of "vascular natriuretic peptide system". J Clin Invest 1992, 90:1145-1149

6. Sogawa C, Wakizaka H, Aung W, Jin ZH, Tsuji AB, Furukawa T, Kunieda T, Saga T: C-type natriuretic peptide specifically acts on the pylorus and large intestine in mouse gastrointestinal tract. Am J Pathol 2013, 182:172-179.

7. Zhang M, Su YQ, Sugiura K, Xia G, Eppig JJ: Granulosa cell ligand NPPC and its receptor NPR2 maintain meiotic arrest in mouse oocytes. Science 2010, 330:366-369.

8. Sogawa C, Tsuji T, Shinkai Y, Katayama K, Kunieda T: Short-limbed dwarfism: slw is a new allele of Npr2 causing chondrodysplasia. J Hered 2007, 98:575-580.

9. Geister KA, Brinkmeier ML, Hsieh M, Faust SM, Karolyi IJ, Perosky JE, Kozloff KM, Conti M, Camper SA: A novel loss-of-function mutation in $\mathrm{Npr} 2$ clarifies primary role in female reproduction and reveals a potential therapy for acromesomelic dysplasia, Maroteaux type. Hum Mol Genet 2013, 22:345-357.

10. Tamura N, Doolittle LK, Hammer RE, Shelton JM, Richardson JA, Garbers DL: Critical roles of the guanylyl cyclase $B$ receptor in endochondral ossification and development of female reproductive organs. Proc Natl Acad Sci U S A 2004, 101:17300-17305.

11. Middendorff R, Davidoff MS, Behrends S, Mewe M, Miethens A, Muller D: Multiple roles of the messenger molecule cGMP in testicular function. Andrologia 2000, 32:55-59.

12. Middendorff R, Muller D, Paust HJ, Holstein AF, Davidoff MS: New aspects of Leydig cell function. Adv Exp Med Biol 1997, 424:125-138.

13. Xia W, Mruk DD, Cheng CY: C-type natriuretic peptide regulates blood-testis barrier dynamics in adult rat testes. Proc Natl Acad Sci U S A 2007, 104:3841-3846.

14. Sogawa C, Abe A, Tsuji T, Koizumi M, Saga T, Kunieda T: Gastrointestinal tract disorder in natriuretic peptide receptor B gene mutant mice. Am J Pathol 2010, 177:822-828.

15. Horn MM, Ramos AR, Winkelmann L, Matte US, Goldani HA, Silveira TR: Seminiferous epithelium of rats with food restriction and carbon tetrachloride-induced cirrhosis. Int Braz J Urol 2006, 32:94-99. discussion 99.

16. Wu A, Wan F, Sun X, Liu Y: Effects of dietary restriction on growth, neurobehavior, and reproduction in developing Kunmin mice. Toxicol Sci 2002, 70:238-244.

17. Kiyosu C, Tsuji T, Yamada K, Kajita S, Kunieda T: NPPC/NPR2 signaling is essential for oocyte meiotic arrest and cumulus oophorus formation during follicular development in the mouse ovary. Reproduction 2012, 144:187-193. 
18. Santos AM, Ferraz MR, Teixeira CV, Sampaio FJ, da Fonte Ramos C: Effects of undernutrition on serum and testicular testosterone levels and sexual function in adult rats. Horm Metab Res 2004, 36:27-33.

19. Zambrano E, Rodriguez-Gonzalez GL, Guzman C, Garcia-Becerra R, Boeck L, Diaz L, Menjivar M, Larrea F, Nathanielsz PW: A maternal low protein diet during pregnancy and lactation in the rat impairs male reproductive development. J Physiol 2005, 563:275-284.

20. Glossmann H, Petrischor G, Bartsch G: Molecular mechanisms of the effects of sildenafil (VIAGRA). Exp Gerontol 1999, 34:305-318.

doi:10.1186/1477-7827-12-64

Cite this article as: Sogawa et al:: Mutant phenotype analysis suggests potential roles for C-type natriuretic peptide receptor (NPR-B) in male mouse fertility. Reproductive Biology and Endocrinology 2014 12:64.

\section{Submit your next manuscript to BioMed Central and take full advantage of:}

- Convenient online submission

- Thorough peer review

- No space constraints or color figure charges

- Immediate publication on acceptance

- Inclusion in PubMed, CAS, Scopus and Google Scholar

- Research which is freely available for redistribution 